Revista Oficial del Poder Judicial

ÓRGANO DE INVESTIGACIÓN DE LA CORTE SUPREMA DE JUSTICIA DE LA REPÚBLICA DEL PERÚ

Vol. 11, n. ${ }^{\circ} 13$, enero-junio, 2020, 551-558

ISSN versión impresa: 1997-6682

ISSN versión electrónica: 2663-9130

DOI: https://doi.org/10.35292/ropj.u11i13.63

\title{
Poder Judicial del Perú. Séptimo Pleno Casatorio Civil. Tercería de propiedad (2. ${ }^{a}$ ed.).
}

Lima: Fondo Editorial del Poder Judicial, 2019, 180 pp.

0

Suelen estar en manos de la Corte Suprema de Justicia de la República las soluciones definitivas a los problemas de interpretación y aplicación del derecho; en ese sentido, uno de los conflictos que ameritaban, desde hace buen tiempo, una respuesta clara eran los procesos donde se discutía - muchas veces, con resultados contradictorios - el derecho de propiedad de un inmueble no registrado, frente a un embargo judicial inscrito sobre el mismo bien, $y$, con ello, el debate respecto a los alcances de lo establecido en el artículo 2022 del Código Civil sobre oponibilidad de derechos, en las demandas de «tercería de propiedad», figura jurídica procesal regulada en el artículo 533 del Código Procesal Civil.

La obra aquí reseñada, titulada Séptimo Pleno Casatorio Civil. Tercería de propiedad, editada por el Fondo Editorial del Poder Judicial, acoge en sus páginas la sentencia casatoria emitida por los jueces supremos civiles reunidos en pleno y las principales piezas procesales que obran en el expediente judicial que fuera resuelto 


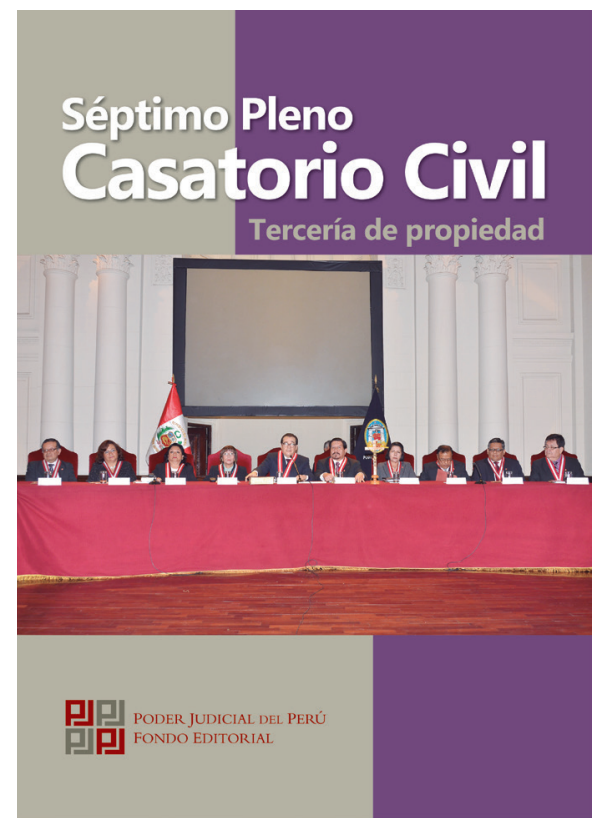

en la Casación n. ${ }^{\circ}$ 3671-2014Lima, proceso que ha dado lugar a la celebración del Séptimo Pleno Casatorio Civil.

Cabe destacar que la publicación impresa ha respetado el contenido original de la sentencia casatoria y de los actuados con la finalidad de que estas lleguen al lector preservando su fidelidad, a lo cual se suma el prolijo cuidado en la edición del libro, tanto en los aspectos gráficos como lingüísticos, que logran, en su conjunto, darle identidad a una obra que ya forma parte del acervo bibliográfico de la nación y constituye una fuente de consulta que se inscribe dentro de los esfuerzos del máximo tribunal de justicia por garantizar la predictibilidad de la justicia civil.

En cuanto a esto último, la sentencia sanciona en su decisión reglas hermenéuticas a las que atribuye el carácter de "precedente judicial vinculante». En este caso, el Supremo Tribunal otorga a su resolución una condición que emana de su propia autoridad, pero lo realmente valioso para el análisis -desde un punto de vista del desarrollo de la doctrina jurisprudencial de la Corte Supremaradica en que la fuerza vinculatoria de la sentencia casatoria emane de la propia consistencia y coherencia de las argumentaciones expuestas en el considerando de la sentencia, y no tanto en una declaración formal.

Dicho ello, en referencia a lo resuelto en sede casatoria, la sentencia del pleno, tras declarar infundado el recurso de casación y no casar la sentencia de vista, fija como precedente judicial vinculante, en su segundo extremo, las siguientes reglas hermenéuticas: 
1. En los procesos de tercería de propiedad que involucren bienes inscritos, debe considerarse, de conformidad con lo dispuesto en la segunda parte del artículo 2022 del Código Civil, en concordancia con los artículos 949 y 1219 inciso $1 .^{\circ}$ del mismo cuerpo legal, que el derecho de propiedad del tercerista es oponible al derecho del acreedor embargante, siempre que dicho derecho real quede acreditado mediante documento de fecha cierta más antigua que la inscripción del embargo respectivo.

2. El juez de primera instancia, de oficio, una vez que sea admitida la demanda, deberá velar por la legalidad de la certificación de la fecha cierta del documento que presente el tercerista. Para tal fin, podrá oficiar al notario, juez y/o funcionario que haya emitido tal certificación, a efectos de que informe sobre la autenticidad o falsedad de la misma.

3. En caso de que el notario, juez o funcionario correspondiente no reconozca la autenticidad de la certificación que se le atribuye en el documento presentado por el tercerista, la demanda deberá ser declarada INFUNDADA, debiéndose expedir las copias certificadas correspondientes al Ministerio Público, para que este actúe conforme a sus atribuciones (p. 99).

En este extremo puede apreciarse que el colegiado se avoca a una interpretación objetiva y sistemática del segundo párrafo del artículo 2022 del Código Civil, con el propósito de despejar dudas respecto a los supuestos de tercería de propiedad que impliquen bienes inmuebles no registrados, y no acoge los criterios registrales dirigidos a hacer prevalecer el crédito inscrito en la forma de embargo judicial sobre la propiedad inmueble no registrada.

Ahora bien, la decisión del pleno fue adoptada en mayoría, lo cual demuestra lo amplio del debate generado; sin embargo, no exime la consideración de los votos singulares suscritos por tres de los integrantes del colegiado. El voto singular de Martínez Maraví precisa que el derecho de propiedad no inscrito y el embargo inscrito son derechos de diferente contenido y excluyentes, pero 
que la norma jurídica aplicable en caso de conflicto entre ambos derechos, esto es, el segundo párrafo del artículo 2022 del Código Civil, no señala con claridad cuál debería prevalecer y remite a «las disposiciones del derecho común», lo cual evidencia que dichas disposiciones tienen que consagrar un criterio de solución distinto al de la inscripción registral consagrado en el primer párrafo del citado artículo, en tanto hipótesis autónomas y contrarias entre sí.

En esa línea, en el citado segundo párrafo se consagra una oración adversativa que niega la afirmación principal del primer párrafo (la primacía de la inscripción registral): «[...] por lo que, la referida oración adversativa vendría a ser la afirmación de que el conflicto entre derechos de diferente naturaleza o contenido se resuelve sin tener en cuenta el Registro» (p. 104); luego, que:

[...] las «disposiciones del derecho común» a que se hace referencia son las normas del artículo $949 .^{\circ}$ y el artículo $1219 .^{\circ}$ inciso 1 del Código Civil, que consagran, la primera, que un adquirente se hace de la propiedad con el solo consenso y, la segunda, que un acreedor no puede afectar bienes que no son de su deudor (p. 107).

Por el contrario, en su voto singular, Calderón Puertas discrepa de la interpretación dada acerca de la segunda parte del artículo 2022 del Código Civil, en el sentido de buscar la repuesta en la distinción entre los derechos nacidos de una obligación (de carácter relativo), que solo vincularía al acreedor con el deudor (inter partes), y aquellos posibles de oponerse a todos (erga omnes), a los que se atribuye una supuesta prioridad. Este último es un supuesto abstracto que impide sostener la superioridad de uno de los derechos (específicamente, de la propiedad no inscrita) respecto al otro (crédito) por su mayor grado de protección y considera que, en este caso de conflicto entre un derecho real y uno obligacional, el derecho de propiedad cede al derecho de crédito, de modo que los datos que brindan los Registros Públicos 
deben otorgar la solución, pues: «cuando el embargo se encuentre inscrito, no tiene por qué perjudicarse al diligente que se vale de los principios de publicidad y legitimación registrales para cautelar su acreencia» (p. 116).

Sin duda, esta reciente jurisprudencia civil casatoria ha generado una saludable deliberación, a nivel de distintos foros académicos, sobre las bondades de lo resuelto. No obstante, dicho problema interpretativo ya era objeto de preocupación por parte de la doctrina; Alexander Rioja (2011), al referirse al principio de prueba escrita del fundamento de la pretensión del tercerista, había llamado la atención sobre la necesidad imprescindible de «que se acredite que la fecha de adquisición sea cierta y confiable y que preceda en el tiempo a la de medida cautelar» (p. 176). Es más, en la Exposición Oficial de Motivos del Código Civil de 1984 -que, en su artículo 2019, inciso 7, siguió considerando al embargo como acto inscribible en el Registro de la Propiedad Inmueble - ya parece darse, como señala Eugenia Ariano (2016), una solución «definitiva» al problema:

Artículo 2022. Para oponer derechos reales sobre inmuebles a quienes también tienen derechos reales sobre los mismos, es preciso que el derecho que se opone esté inscrito con anterioridad al de aquel a quien se opone.

Si se trata de derechos de diferente naturaleza, se aplican las disposiciones del derecho común.

Sin embargo, la precitada autora, tras constatar - no sin misterio ni asombro- que en el caso de otros actos inscribibles, regulados en el código sustantivo, el «derecho común» es dejado de lado en beneficio de la aplicación de la regla de la prioridad de la inscripción, con la sola excepción del embargo - el cual también es inscribible-, así como que el Código Procesal Civil vigente -que debió tomar una expresa posición al respecto- no ofrece 
alguna solución al problema y que la tendencia mayoritaria en la jurisprudencia se ha inclinado a favor del adquirente de derechos reales anteriores a la anotación, observa que la sentencia del VII Pleno Casatorio Civil establece como precedente judicial vinculante «[...] nada distinto del criterio mayoritario [...]» (Ariano, 2016, p. 182); es decir, que:

[...] pese a todo su esfuerzo por interpretar objetivamente el texto del segundo párrafo del artículo 2022 del Código Civil, no han encontrado otra salida que remitirse (como lo quería el legislador concreto, esto es, el que escribió el artículo 2022 del Código Civil), para resolver el conflicto planteado en una tercería de propiedad, al derecho común ( $\mathrm{y}$ no al derecho registral) (Ariano, 2016, p. 183).

Un aspecto destacable en la sustanciación de este caso complejo fue la participación de los llamados amicus curiae o «amigos del tribunal», especialistas cuyos enfoques académicos fueron compartidos por el colegiado supremo en sus aspectos centrales, divergentes, sea en favor de la defensa de la propiedad (posición mayoritaria) o de protección del embargo inscrito, excepto por el profesor Juan Monroy, cuya intervención es reseñada en el considerando 5.3 de la resolución:

Juan Monroy sostuvo que el caso discutido no debería ser objeto de un precedente vinculante, pues: (1) El artículo 2022 al clasificar los derechos en personales y reales incurre en un anacronismo. Esa clasificación era históricamente entendible, pero hoy no tiene ningún significado y se encuentra superada; (2) La tercería no tiene por objeto titular con el derecho de propiedad a nadie, sino liberar un bien afectado por una medida cautelar, finalidad que debe tenerse en cuenta; (3) El sistema de transferencia de propiedad inmobiliaria regulada en el sistema civil es desconocido por las grandes mayorías. Por ello, deben ser 
los jueces en el caso concreto los que resuelvan atendiendo a las especiales connotaciones del caso particular, razón por la cual no debiera generarse un precedente con alcance general.

Dicha posición, si bien discrepante, con la convocatoria a pleno, al considerar que «El sistema de transferencia de propiedad inmobiliaria regulada en el sistema civil es desconocido por las grandes mayorías»(p. 76), refleja hechos reveladores: no solo el desconocimiento general de una norma - en teoría inexcusable-, sino, a su vez, la falta de dominio de la correcta interpretación y aplicación de una determinada figura jurídica, incluso por los propios letrados y operadores del sistema de justicia. Ello es una de las causas de conflictos y procesos judiciales que bien podrían evitarse, pero que, además, en el caso de una materia compleja, da lugar a jurisprudencia contradictoria, afectando sensiblemente la predictibilidad de la justicia y la seguridad jurídica.

En tal sentido, la Corte Suprema de Justicia cumple, a través de su jurisprudencia casatoria, no solo un rol unificador, cerrándole el paso a la jurisprudencia contradictoria, sino también una función educativa, por tratarse de la más alta judicatura del país, cuyas sentencias contienen valiosas pautas hermenéuticas que orientan la actividad jurisdiccional, así como contenidos ilustrativos y pedagógicos en el ámbito de la cultura jurídica, la justicia y el derecho. De ahí la importancia de que los tribunales de justicia estén constituidos por jueces con una sólida formación académica y humanística, que les permita resolver, con criterio de justicia, la compleja carga procesal, máxime en graves tiempos de crisis social e institucional.

La publicación, por el Fondo Editorial del Poder Judicial, del libro Séptimo Pleno Casatorio Civil da cuenta, entonces, de cómo la Corte Suprema de Justicia de la República — de momento- ha zanjado el problema hermenéutico subyacente a la figura de la 
«tercería de propiedad» en la resolución de los casos de conflicto entre el derecho real de propiedad no inscrito y el derecho obligacional inscrito en la forma de embargo; todo ello en aras de la predictibilidad de las decisiones judiciales en este ámbito del derecho judicial. Pero, lejos de señalar que es un capítulo cerrado, consideramos que la sentencia casatoria ha reavivado y enriquecido el debate en torno a esta temática. Por ello, invitamos a que se consulte su versión impresa, que ha sido editada con esmerado cuidado y rigurosidad.

\section{REFERENCIAS}

Ariano, E. (2016). El embargo castigado: consideraciones (ya) inactuales sobre un viejo problema tratado de superar con el VII Pleno Casatorio Civil (Sentencia de Casación n. ${ }^{0}$ 3671-2014Lima). Ius et Veritas, 24(52), 160-192.

Rioja, A. (2011). En defensa de la propiedad indebidamente embargada. Revista Oficial del Poder Judicial. Órgano de Investigación de la Corte Suprema de Justicia de la República del Perú, (6-7), 163-188.

Jorge Angel Chávez Descalzi Centro de Investigaciones Judiciales del Poder Judicial (Lima, Perú)

Contacto: jchavezd@pj.gob.pe https://orcid.org/0000-0003-4653-7922 